\title{
Contribution to the Identification of Antibiotics Residues in Raw Bovine Milk in Algeria
}

\author{
Lyes Ouabdesselam ${ }^{1,2 *}$, Zoubir Benmaamar ${ }^{3}$, Ali Berbar ${ }^{2}$
}

\author{
${ }^{1}$ Food Science Division, Center for \\ Research and Physical-Chemical \\ Analysis (CRAPC), Bou-Ismail, Tipaza, \\ ALGERIA \\ ${ }^{2}$ National Institute of Veterinary \\ Sciences, SAAD DAHLEB University of \\ Blida, Route de Soumâa, BP 270, Blida \\ RP 09000, ALGERIA \\ ${ }^{3}$ Faculty of Chemistry, SAAD DAHLEB \\ University of Blida, Route de Soumâa, \\ BP 270, Blida RP 09000, ALGERIA \\ * Corresponding author: \\ ouabdesselam.lyes@crapc.dz
}

\section{EUROPEAN JOURNAL OF BASIC MEDICAL SCIENCE}

Eur J Basic Med Sci 2020;10(1):43-46

Received: 10 Aug 2020

Accepted: 5 Oct 2020

\begin{abstract}
The presence of residues of veterinary drugs such as antibiotics used for the treatment of animals can be dangerous for the consumer. Indeed, residues of these drugs can end up in the form of undesirable traces in animal productions, in particular milk when there is an inappropriate use such as failure to comply with the waiting times between the administration of antibiotics to the animal and meat collection. This study is part of a global project carried out with the aim of evaluating the presence of antibiotic residues in the raw milk of cows reared in cattle farms in Blida. This study involved 200 milk samples were collected in the Wilaya of Blida. A screening of the samples was carried out by the acidification test followed by a confirmation agar diffusion test. The results showed residues in $20.51 \%$ of the milk tested. The study revealed the presence of antibiotic residues in raw cow's milk from farms in varying proportions. Penicillin residues and / or tetracyclines were originally of the contamination of $93.62 \%$ milk samples positive while residues macrolide and / or aminoglycoside were only detected in $6.38 \%$ of samples tested positive. The use of antibiotics should be done by veterinarians or under their responsibility by animal health professionals.
\end{abstract}

Keywords: raw milk, bovine, contamination, antibiotic residues, Algeria, Blida 


\section{INTRODUCTION}

Algeria is the leading dairy consumer in the Maghreb with 115 liters / inhabitant / year in 2016 and a milk market estimated at 5 billion liters per year [1]. This growing demand is a corollary to the development of mass distribution and local processing industries. This rapid development in demand leads to changes in behavior with fraudulent sanitary practices, due to a proliferation of breeding aids that are difficult to control, for a rapid gain. The presence of antibiotic residues in milk constitutes a danger for the consumer by provoking the development of resistance to antibiotics by promoting the emergence of a multiresistant microflora. It may December lencher toxic accidents or even rarely allergic disorders [2]. The problem of residues can also be the cause of the total or partial inhibition of fermentation phenomena of bacterial origin in dairy products such as yoghurts and cheeses, which represents an economic loss for the dairy industry. The purpose of this study is to identify antibiotic residues in raw milk produced in the Wilaya of Blida (Algeria).

\section{MATERIAL AND METHODS}

\section{Material}

In this study, we realized 200 samples so divided homogeneous four breeding $s$ sedentary previously identified in the region of Blida (Algeria). Two collections of $500 \mathrm{ml}$ of raw milk were carried out at an interval of 15 days in each of the breeding farms. The first collection was made at least one month after the administration of an antibiotic treatment ti the animals on the basis of the declarations made by the breeders. Other collection s are interveneds 15 days after the first collection. The raw milk samples collected from each breeding farm were taken from the bucket or plastic bowl in which the milk is collected. The milk was packaged in sealed plastic bottles, labeled and identified according to the farm number. In total, 200 raw milk samples were collected by area in the course of the period of collection and transported under cooler Laboratory. Then the milk samples were placed in the freezer at $-20^{\circ} \mathrm{C}$ for storage [3].

\section{Methods}

Milk samples collected from the three wilayas will be subjected to an acidification test to carry out an initial screening followed by diffusion in agar [4].
Two techniques were successively implemented: An acidification test which is based on the demonstration of a possible inhibition of Bacillus stearothermophilus var. calidolactis C953 (strain C953, CIP 5281) indicated by the turn of colored indicator antibiotic residues which would be present in the sample. Follow-up by a confirmatory test, corresponding to the performance of two agar diffusion tests, one with Bacillus subtilis (ATCC 6633 , spore suspension) at $30^{\circ} \mathrm{C}$ and the other with Bacillus stearothermophilus variety calidolactis at $55^{\circ} \mathrm{C}[4,5]$.

\section{Acidification test}

The milk sample is seeded with $B$. spores. stearothermophilus in a nutrient peptone agar medium, comprising bromocresol purple and trimethoprim, for $2^{\mathrm{h}} 30^{\mathrm{min}}$ at $64^{\circ} \mathrm{C}$. A negative control (reconstituted milk powder certified free from antibiotic residues) and a positive control (milk containing $0.01 \mathrm{IU} / \mathrm{ml}$ of control penicillin) are incubated in the presence of $0.1 \mathrm{ml}$ of the test culture. under the same conditions and at the same time as the samples to be tested [5].

\section{Agar diffusion method}

The Muller Hinton agar medium, previously melted at $100^{\circ} \mathrm{C}$ and cooled to $55^{\circ} \mathrm{C}$, is poured into Petri dishes. The medium was then inoculated with $B$. subtilis and $B$. stearothermophilus spores at $10^{3}$ and $10^{5}$ spores $/ \mathrm{ml}$. The sterile filter paper discs, impregnated with the milk to be tested by capillarity were then placed on the surface of the agar and the Petri dishes were incubated at $55^{\circ} \mathrm{C}$ (B. stearothermophilus) and $30^{\circ} \mathrm{C}$ (B. subtilis).). After $24 \mathrm{~h}$ of incubation, the diameters of the zones of inhibition were measured using a caliper [5].

\section{RESULTS}

\section{Acidification Test Results}

The purple color of the persistent blue bromocrésol was recorded for 41 samples of the 200 tested $(20.51 \%)$, reflecting the presence of antibiotic residues. On the other hand, a color change was observed for 153 samples $(76.49 \%)$ which were declared negative. It was impossible to etablisch a conclusion for 06 samples (3\%) considered as impaired (Table 1). 
Dhotre et al.

Table 1. Demonstration of antibiotic residues in cow's milk by the acidification test / Region of Blida (Algeria)

\begin{tabular}{ccccc}
\hline Samples & Number & Negatives (\%) & Suspect (\%) & Positives (\%) \\
\hline Total (\%) & 200 & $76.49 \%$ & $03 \%$ & $20.51 \%$ \\
\hline
\end{tabular}

Table 2. Demonstration of antibiotic residues in cow's milk by the Agar Diffusion Confirmation test / Region of Blida (Algeria)

\begin{tabular}{cccccc}
\hline Wilaya & Number of samples positive & For B. stearothermophilus & $\%$ & For B. subtilis & $\%$ \\
\hline Blida & 47 & 44 & 93.62 & 3 & 6.38 \\
\hline
\end{tabular}

\section{Agar Diffusion Confirmation Test}

\section{See Table 2.}

\section{INTERPRETATIONS AND DISCUSSION}

This study you confirmed that the contamination rate was on the Qurante Seven (47) positive samples with antibiotic residues, a percentage of $93.62 \%$ of the samples were positive for penicillin and / or tetracyclines. A percentage of $6.38 \%$ were positive for macrolides and / or aminoglycosides (Table 2). Fortyfour (44) of the 47 tested exhibited an annular zone of inhibition of $B$. stearothermophilus with a diameter greater than $12.67 \mathrm{~mm} \pm 0.72 \mathrm{~mm}$. These samples were considered positive for penicillin and / or tetracycline residues. Three (3) samples out of the 47 tested were found to be positive for macrolide and / or aminoglycoside residues by inducing a circular inhibition of $11.18 \mathrm{~mm} \pm 1.09 \mathrm{~mm}$ of the colonies of $B$. subtilis. These results demonstrate the wide use of penicillins and tetracyclines in the treatment of infections in dairy farming in Algeria. Particularly for mastitis by injected ions intramammary. The microbiological analysis method implemented using B.stearothermophilus as a test microorganism is characterized by an antibiotic detection threshold as close as possible to the maximum residue limits (MRLs) of the antibiotics most frequently used in the treatment of cattle. dairy while maintaining a broad spectrum of antibiotics. In fact, the sensitivity of the new acidification technique is much better for the two families of antibiotics most widely found in the intramammary specialties used in Algeria (beta- lactams and tetracyclines). In fact, Bacillus stearothermophilus is characterized by a remarkable sensitivity to beta lactams, its growth is inhibited by a concentration of 5 $\mathrm{ppb}$ of ampicillin [6]. The sensitivity of this technique is particularly high for cloxacillin and relatively acceptable for tetracycline [7]. The acidification technique is thus characterized by a sensitivity close to the MRL for cloxacillin and $50-100 \%$ of the MRL for tetracycline compared to the old method using
Streptococcus thermophilus as a test microorganism which does not offer two previously cited antibiotics that have respective sensitivity of 3 to 4 times the MRL and 2-4 times the MRL. The risk of false negative results with milk with a very low concentration of antibiotic residues close to the MRLs is thus limited. The confirmation test shows great specificity [8].

\section{CONCLUSION}

The growing and sometimes irrational use $[9,10]$ of antibiotics produced by the non-respect of time $s$ waiting results in the presence of residues in milk produced by cows treated and is a real public health problem in Algeria [9] given the danger of resistance to antibiotics incurred by the end consumer. This risk is low in the formal controlled circuit [11]. The dairy industry in Algeria remained for many years the property of the State. The establishment of private collectors encouraged by the public authorities, and this since 2000, has not kept all its promises; since the quantities collected have always remained very low. The commitment of dairies to farmers is almost insignificant [12], above all. The specialization of these farms is imprecise; informal collection is therefore very present and is required despite all the efforts made by the public authorities to formalize this entire segment. It is evident that in view of the large quantities of milk production (over 96\%) which escape formal circuits [13]. The art public policies in this area are ineffective. While competing with each other, the two types of sectors are highly interdependent. They meet food needs not covered by legal businesses and largely contribute to supplying urban populations. The control of the sanitary quality of milk must be further strengthened by the State.

\section{ACKNOWLEDGEMENTS}

Our sincere thanks go to the Personnel of National Institute of Veterinary Science (INSV) from SAAD DAHLEB University (Blida) and the Center for Research in Physico-Chemical analysis (CRAPC) sis Tipaza. 


\section{Conflict of Interest: None to Declare}

Source of funding: No funding

\section{REFERENCES}

1. Benbouali S. Analysis and market potential report - "The Agri-Food Industries market in Algeria " published in June 2017 by the Business France Office. Available at: https://www.djazagro.com/ Le-salon/Actualites/La-Production-Algerienne

2. Aning KG, Donkor ES, Omore A, Nurah GK, Osafo ELK, Staal S. Risk of exposure to marketed milk with antimicrobial drug residues in Ghana. The Open Food Science Journal 2007 ; 1: 1-5. Available at: http://hdl.handle.net/10568/795

3. Ouabdesselam L, Saadi A, Harhoura K. Contribution to the Assessment of Suitability to Cheese Processing of Milk of Some Bovine Breeds in the Region of Algiers, International Journal of Science and Research (IJSR), 2017; 6(1): 1085-9. doi: 10.21275/ART20164126.

4. Sulejmani Z, Shehi A, Hajrulai Z, Mata E. Abuse of pharmaceutical drugs-antibiotics in dairy cattle in Kossovo and detection of their residues in milk. J Ecosyst Ecogr. 2012; 2: 114 . doi: 10.4172/21577625.1000114.

5. European decision $91 / 180$ CEE; EC Regulation $\mathrm{N}^{\circ}$ 1664/2006. Official European method of detection of residues of antibiotics in the milk applied in the community EU since 1 January, 2002.

6. Basic Tests for Pharmaceutical Dosage Forms; World Health Organization. Detection of Ampicillin in milk supernatant, 1986; 3: 17.
7. Basic Tests for Pharmaceutical dosage forms, World Health Organization; Detection of Oxytetracycline (OTC) in milk supernatant, 1986; 1 \& 3: 122.

8. Ivona K, Mate D. Evaluation of the sensitivity of individual test organisms to residual concentrations of selected types of drugs. Slovenian Veterinary Research, 2002; 9: 78-82.

9. Abdeljalil MC. Sanitary and zootechnical monitoring at the level of dairy cow farms. Mentouri University of Constantine, Algeria. 2005.

10. Massai Ahmed, Benmakhlouf A. Critical analysis of antibiotic therapy practices in poultry farming, 100: 102-33.

11. Hammami M, Elmi Soltani E, Bouraqui R. Impact of the national agricultural regulation and development fund on the sustainability of dairy cattle in the wilaya of Tizi-ouzou (Algeria). New Medit, 2011; 3: 22-7.

12. Urban food supply in a transitional economy: The case of the distribution of milk and milk products from ORLAC in the city of Algiers. International Center for Advanced Mediterranean Agronomic Studies / Mediterranean Agronomic Institute, Montpellier. Master of Sciences thesis. Bourbouze A., 2003.

13. Djermoun A. The circuits used by local milk in Chéliff in Algeria: importance of the informal circuit. Livestock research for rural development, 2011; 22. 